\title{
Aplikasi Genetika Untuk Penjadwalan Mata Pelajaran di SMAN 3 Semarang
}

\author{
Genetic Application for School Scheduling at SMAN 3 Semarang
}

\author{
Restu Agung Pamuji ${ }^{1}$, Junta Zeniarja ${ }^{2}$, Abu Salam ${ }^{3}$ \\ Teknik Informatika, Fakultas Ilmu Komputer, Universitas Dian Nuswantoro \\ e-mail: ${ }^{1} 111201307641 @$ mhs.dinus.ac.id, 2junta@dsn.dinus.ac.id, 2abu.salam@dsn.dinus.ac.id
}

\begin{abstract}
Abstrak
Merencanakan kegiatan belajar mengajar di sekolah sangat penting dan rumit. Ini bukan masalah serius ketika sekolah memiliki sejumlah kecil kelas dengan minimal pertemuan belajar mengajar. Tetapi itu akan menjadi masalah dalam hal jumlah kelas, ruang dan jumlah guru yang terbatas. Contoh masalah yang sering muncul adalah sulitnya menempatkan slot waktu untuk menghindari bentrokan. Untuk alasan ini, diperlukan suatu aplikasi untuk membangun sistem perencanaan dengan meminimalkan kesalahan perencanaan sehingga kegiatan pembelajaran dapat dilakukan secara optimal. Metode penjadwalan pelajaran ini menggunakan pendekatan algoritma genetika. Algoritma genetika merupakan pendekatan komputer yang diinspirasi oleh teori genetika untuk menyelesaikan masalah yang memerlukan optimasi. Hasil penerapan algoritma genetika sebagai pendekatan untuk mengoptimalkan perencanaan mata pelajaran sekolah telah menghasilkan nilai fitness yang optimal. Kemudian diuji dari faktor correctness, menghasilkan sejumlah error hingga 0 baris. Diuji secara fungsional tidak menghasilkan fungsi primer dan sekunder yang tidak berfungsi dengan benar. Diuji dengan faktor portabilitas dalam mencoba berbagai aplikasi, dapat bekerja dengan baik di semua lingkungan.
\end{abstract}

Kata kunci : Penjadwalan, Algoritma Genetika

\begin{abstract}
Planning teaching and learning activities in schools is very important and complicated. This is not a serious problem when schools have a small number of classes with a minimum of teaching and learning meetings. But that will be a problem in terms of the number of classes, space and the limited number of teachers. An example of a problem that often arises is the difficulty of placing a time slot to avoid clashes. For this reason, an application is needed to build a planning system by minimizing planning errors so that learning activities can be carried out optimally. The method of scheduling this lesson uses a genetic algorithm approach. Genetic algorithms are computer approaches that are inspired by genetic theory to solve problems that require optimization. The results of the application of genetic algorithms as an approach to optimize school planning have resulted in optimal fitness values. Then tested from the correctness factor, resulting in a number of errors up to 0 lines. Functionally tested does not produce primary and secondary functions that do not function properly. Tested with portability factors in trying various applications, it can work well in all environments.
\end{abstract}

Keywords : Scheduling, Genetic algorithm 


\section{PENDAHULUAN}

Pendidikan merupakan hal pokok dalam pembentukan generasi penerus yang unggul, berkualitas dan mempunyai moral yang baik sehingga mampu bersaing dengan perkembangan zaman dan teknologi. Semakin baik pendidikan maka semakin banyak program dan permasalahan yang harus dikerjakan sedemikian rupa demi kelanjutan dan masa depan pendidikan tersebut. Dengan adanya teknologi, sekolah bisa memanfaatkanya untuk membantu penataan program-program pendidikan dan semua kegiatan didalamnya, oleh karena itu dibuatlah sistem informasi untuk menunjang keberlangsungan pendidikan. Dengan adanya sistem informasi pendidikan, sekolah dapat memberikan sarana kepada seluruh bagian yang ada di bidang pendidikan agar dapat berperan aktif dalam memajukan pendidikan. Kemudian dapat meningkatkan wawasan guru dan murid tentang informatika dan manfaat yang dapat diambil. Dan juga dengan adanya sistem informasi dapat memberikan informasi secara transparan tentang kebijakan pemerintah dan pemakaian sumber daya yang dialokasikan untuk pendidikan. SMAN 3 Semarang sebagai sekolah menengah atas memiliki permasalahaan mengenai penjadwalan yang konvensional. Di antaranya adanya jadwal yang mengikat, jumlah guru terbatas, dan ada parameter-parameter tertentu. Proses pembuatan jadwal masih dilakukan secara manual dan belum memiliki model optimasi dengan aplikasi.

Algoritma genetika merupakan suatu teknik optimalisasi dan pencarian yang berdasar pada prinsip genetika dan seleksi alam (evolusi biologi). Algoritma genetika dikembangkan pertama kali oleh John Holland dengan muridnya yang bernama DeJong. Algoritma genetika merupakan algoritma pencarian heuristik yang didasarkan atas mekanisme evolusi biologis. Keberagaman pada evolusi biologis adalah variasi dari kromosom antar organisme. Variasi kromosom akan mempengaruhi laju reproduksi dan tingkat kemampuan organisme dalam bertahan hidup [1].

Penulis mengusulkan menggunakan algoritma genetika karena merupakan salah satu penerapan dari algoritma genetika, yaitu masalah optimasi yang dalam hal ini adalah optimalisasi penjadwalan, untuk mendapatkan nilai solusi optimal dari masalah yang memiliki banyak kemungkinan solusi. Daya tarik algoritma genetika terletak pada kesederhanaan dan kemampuan untuk menemukan solusi yang baik dan cepat untuk masalah yang rumit. Beberapa keunggulan termasuk menghubungkan sejumlah besar variabel, memberikan daftar variabel optimal bukan hanya solusi tunggal, tetapi juga dapat mengkodekan variabel sehingga optimasi dilakukan dengan mengkodekan variabel dan bekerja dengan jumlah data yang dihasilkan. Algoritma genetika mempunyai beberapa kelebihan yang diantaranya berkaitan sejumlah besar variabel, pemberian daftar variabel yang optimal bukan hanya solusi tunggal, dapat menyandikan variabel sehingga optimasi dilakukan dengan dengan mengkodekan variabel dan bekerja dengan data numerik yang dihasilkan [2].

Hal yang sama juga dikemukakan oleh peneliti lain bahwa dengan bantuan Algoritma Genetika, jadwal penjadwalan dapat dioptimalkan. Program tersebut akan mencari solusi pemrograman pada waktu yang dapat digunakan oleh siswa dan ruangan yang terhubung dengan mata kuliah[3]. Selain itu, penerapan algoritma genetika dalam pemrograman subjek memiliki kinerja yang cukup baik. Semakin besar jumlah kromosom yang dihasilkan, semakin rendah jumlah kejutan yang terjadi, semakin baik solusi yang dihasilkan dan, berdasarkan hasil analisis, akan ditemukan bahwa kinerja algoritma genetika cukup baik untuk menyelesaikan masalah penjadwalan mata pelajaran [4]. Dari uraian sebelumnya dapat disimpulkan bahwa algoritma genetika adalah algoritma pencarian berbasis populasi yang cukup optimal untuk digunakan untuk penjadwalan [5].

\section{METODE PENELITIAN}

Algoritma genetika merupakan metode untuk menentukan optimasi. Langkah prosedur algoritma ini dimulai dengan menentukan serangkaian solusi potensial dan membuat perubahan dengan beberapa iterasi dengan algoritma genetika untuk menghasilkan solusi terbaik seperti pada 
gambar 1. Serangkaian solusi potensial ini ditetapkan di awal dan disebut kromosom. Kromosom terbentuk secara acak dalam bentuk angka biner yang dihasilkan dan dipilih. Seluruh set kromosom yang diamati mewakili suatu populasi. Kromosom mengembangkan beberapa iterasi, setelah itu dihasilkan oleh persilangan dan mutasi. Persilangan meliputi pembagian atau pemecahan dua kromosom, kemudian kombinasi dari masing-masing kromosom dengan pasangan lainnya. Mutasi termasuk membalik sedikit (bagian) dari satu kromosom dengan bagian lain dari kromosom yang sama. Kromosom kemudian berevolusi dengan kriteria fitness yang telah ditentukan, hasil terbaik akan dipilih dan yang lainnya akan diabaikan. Proses ini dilakukan berulang kali hingga Anda menemukan kromosom yang memiliki kemampuan terbaik untuk digunakan sebagai solusi terbaik untuk suatu masalah [3].

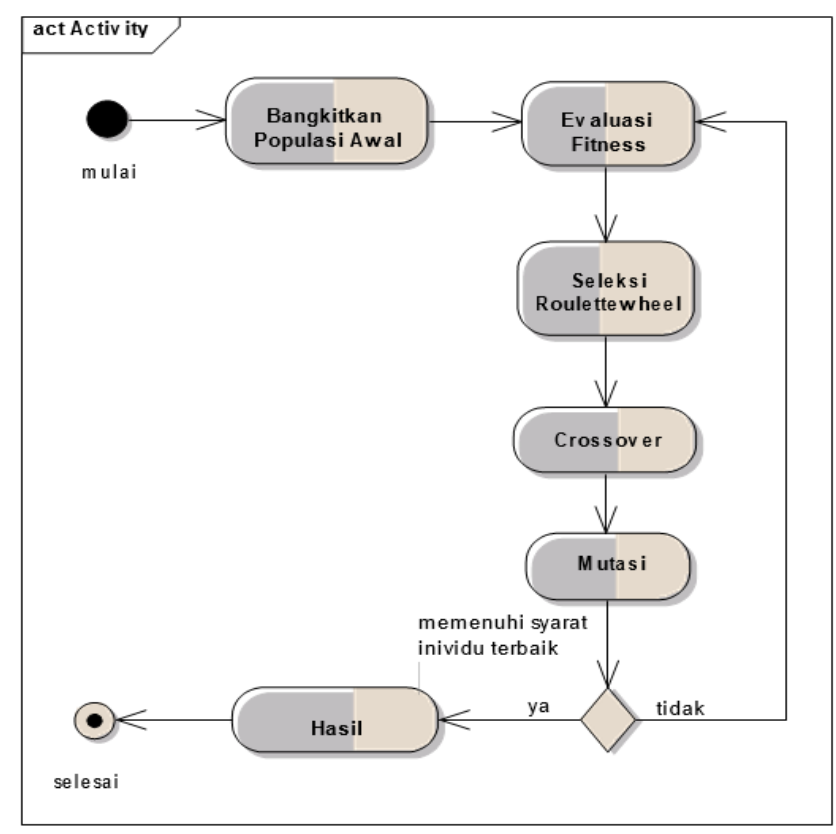

Gambar 1. Flowchart Algoritma Genetika

1. Bangkitkan Populasi Awal

Menghasilkan populasi awal acak terdiri dari sejumlah kromosom yang menyajikan solusi yang diinginkan. Di mana setiap kromosom terdiri dari gen-gen dan setiap gen dalam hal ini adalah mata pelajaaran dan guru yang mengajar guru.

2. Evaluasi Fitness

Sebelum Algoritma Genetika dijalankan, perlu untuk mendefinisikan fungsi fitness sebagai masalah yang ingin dioptimalkan. Jika nilai fitness semakin besar, sistem yang dihasilkan semakin baik.

Fitness $=\frac{1}{1+\text { Error }} \cdot 100$

Kondisi yang mempengaruhi nilai error ada 2 yaitu :

1. Jika ditemukan guru mengajar pada pertemuan yang sama (bentrok jam mengajar).

2. Mata pelajaran olahraga berada diluar jam pagi (ketentuan jam pagi adalah pertemuan ke $1-6)$.

Error $=\sum B p \sum N p$

Bp : Bobot pelanggaran

$\mathrm{Np}$ : Indikator pelanggaran 
Fitness $=\frac{1}{1+\sum B p \sum N p}$

3. Seleksi

Proses seleksi adalah proses untuk menentukan kromosom mana saja yang nantiakan dipilih untuk dilakukan crossover. Seleksi yang diterapkan yaitu roulette-wheel dimana masing-masing dari kromosom menempati potongan lingkaran pada roda roulette secara proporsional sesuai dengan nilai fitnessnya.

4. Crossover

Proses persilangan ini akan bertukar data atau informasi genetik antara dua kromosom induk yang dipilih dari proses seleksi untuk membentuk dua anak. Operator persimpangan bekerja pada sepasang kromosom induk untuk menghasilkan dua kromosom anak dengan bertukar beberapa elemen (gen) yang menjadi milik setiap kromosom induk [6].

5. Mutasi

Mutasi pada umumnya digunakan untuk mencegah hilangnya informasi sehingga dilakukan dengan bertukar informasi pada kromosom. Operator mutasi dapat bersifat konstruktif atau merusak kromosom, tetapi karena probabilitasnya yang kecil, mutasi akan menjadi sangat kecil karena didominasi oleh operator yang menyilang.

6. Kriteria berhenti

Kriteria berhenti yaitu kriteria yang digunakan untuk menghentikan proses Algoritma Genetika yang merupakan tujuan yang ingin dicapai dari proses tersebut antara lain:

a) Berhenti pada individu tertentu.

b) Berhenti setelah dalam beberapa kromosom berturut-turut didapatkan nilai

7. Hasil probabilitas tertinggi tidak berubah. Genetika.

Hasil merupakan solusi terbaik yang didapat dengan menggunakan Algoritma

\section{HASIL DAN PEMBAHASAN}

Hasil penerapan dan perancangan untuk setiap bagian sistem Algoritma Genetika Penjadwalan Mata Pelajaran Sekolah adalah sebagai berikut:

1. Pembangkitan Kromosom

Misal mata pelajaran yang direpresentasikan dalam bentuk kode angka adalah :

Data awal : $(11,7,13,5,15,12,1,3)$.

Acak data awal ke-1 $:(1,3,13,5,11,7,15,12)$ Acak data awal ke-2 $:(13,5,11,7,15$, $12,1,3)$ dst..

Mata pelajaran ini akan di acak sehingga dihasilkan data yang tidak menentu beraturan dan proses acak data ini akan di ulangi sebanyak kelas yang ada.

mapel[kromosom[b]][kelas[c]][pertemuan[d]];

guru[kromosom[b]]kelas[c]][pertemuan[d]];

Array yang digunakan adalah array 5 dimensi dengan keterangan sebagai berikut :

Misal mapel : mapel[i] [i] $[\mathrm{i}]=[\operatorname{kodemapel}[\mathrm{i}]$, $\operatorname{kodemapel}[\mathrm{i}], \ldots]$

mapel $[1][1][1]=[1,13,11,15, \ldots]$

Mapel untuk kelas ke-1 pertemuan ke-1

Index array mewakili kelas (42) dan loop kelas sebanyak pertemuan (46)

Misal guru : guru[i][i][i] $=[\operatorname{kodeguru}[\mathrm{i}]$, $\operatorname{kodeguru}[\mathrm{i}], \ldots]$

$\operatorname{guru}[1][1][1]=[57,76,8,52, \ldots]$

Guru untuk kelas ke-1 pertemuan ke-1

Index array mewakili guru maple 
Tabel 1. Contoh Tabel Jadwal Dengan Kode Huruf

\begin{tabular}{llllll}
\hline \multirow{2}{*}{ Pertemuan } & \multicolumn{1}{c}{$\mathbf{1}$} & \multicolumn{1}{c}{ 2 } & \multicolumn{1}{c}{$\mathbf{3}$} & \multicolumn{1}{c}{$\mathbf{4}$} & $\ldots$ \\
\hline $1-->$ & PH,PH1 & PH,PH1 & IN,IN2 & SP,SP3 & $\ldots$ \\
$2-->$ & SP,SP2 & SP,SP2 & SP,SP2 & CH,CH1 & $\ldots$ \\
$3-->$ & EN,EN1 & EN,EN1 & CH,CH2 & SP,SP1 & $\ldots$ \\
$4-->$ & IN,IN1 & IN,IN1 & EN,EN2 & EN,EN2 & $\ldots$ \\
$\ldots .$. & $\ldots$. & $\ldots$. & $\ldots .$. & $\ldots$. & $\ldots$. \\
\hline
\end{tabular}

Tabel 2. Contoh Tabel Penjadwalan Dengan Kode Angka

\begin{tabular}{llllll}
\hline $\mathbf{1 ~ - - >}$ & 1,57 & 13,76 & 11,8 & 15,52 & $\ldots$ \\
$\mathbf{2 ~ - - >}$ & 1,57 & 13,76 & 11,8 & 15,52 & $\ldots$ \\
$\mathbf{3 ~ - - >}$ & 3,63 & 5,14 & 7,31 & 12,81 & $\ldots$ \\
$\mathbf{4 ~ - - >}$ & 3,63 & 5,14 & 7,31 & 12,81 & $\ldots$ \\
$\ldots$ & $\ldots$ & $\ldots$ & $\ldots$ & $\ldots$ & $\ldots$ \\
\hline
\end{tabular}

Tabel 3. Contoh Tabel Penjadwalan Dengan Nama Mapel

\begin{tabular}{|c|c|c|c|c|c|}
\hline X MIPA 1 & $\begin{array}{l}\text { Matematika, } \\
\text { Mr X57 }\end{array}$ & $\begin{array}{l}\text { Agama, } \\
\text { Mr X76 }\end{array}$ & $\begin{array}{l}\text { Biologi, } \\
\text { Mr X8 }\end{array}$ & $\begin{array}{l}\text { Bhs. Jepang } \\
\text {, Mr X52 }\end{array}$ & $\ldots$ \\
\hline X MIPA 2 & $\begin{array}{l}\text { Matematika, } \\
\text { Mr X57 }\end{array}$ & $\begin{array}{l}\text { Agama, } \\
\text { Mr X76 }\end{array}$ & $\begin{array}{l}\text { Biologi, } \\
\text { Mr X8 }\end{array}$ & $\begin{array}{l}\text { Bhs. Jepang } \\
\text {, Mr X52 }\end{array}$ & $\ldots$ \\
\hline X MIPA 3 & $\begin{array}{l}\text { Fisika, } \\
\text { Mr X63 }\end{array}$ & $\begin{array}{l}\text { Kimia, } \\
\text { Mr X14 }\end{array}$ & $\begin{array}{l}\text { Bhs. Inggris } \\
\text {, Mr X31 }\end{array}$ & $\begin{array}{l}\text { Olahraga, } \\
\text { Mr X81 }\end{array}$ & $\ldots$ \\
\hline X MIPA 4 & $\begin{array}{l}\text { Fisika, } \\
\text { Mr X63 }\end{array}$ & $\begin{array}{l}\text { Kimia, } \\
\text { Mr X14 }\end{array}$ & $\begin{array}{l}\text { Bhs. Inggris } \\
\text {, Mr X31 }\end{array}$ & $\begin{array}{l}\text { Olahraga, } \\
\text { Mr X81 }\end{array}$ & $\ldots$ \\
\hline$\ldots$ & $\ldots$ & $\ldots$ & $\ldots$ & $\ldots$ & $\ldots$ \\
\hline
\end{tabular}

2. Perhitungan nilai fitness

Fungsi objektif dan tingkat error pada sistem tabel diatas ditentukan dari parameter sebagai berikut:

1. Terjadinya kemunculan pertemuan kode guru sama antar kelas .

2. Adanya mapel olahraga pada jam di luar jam pagi (diluar jam pertemuan ke $1,2,3,4,5$ dan 6 pada hari tersebut).

Tabel 4. Parameter perhitungan nilai error

\begin{tabular}{llllll}
\hline $\mathbf{1 ~ - - >}$ & 1,57 & 13,76 & 11,8 & 12,81 & \\
$\mathbf{2}$--> & 1,57 & 13,76 & 11,8 & 12,81 & \\
$\mathbf{3 ~ - - >}$ & 3,63 & 5,14 & 7,31 & 12,81 & \\
$\mathbf{4}$--> & 3,63 & 5,14 & 7,31 & 1,8 & \\
$\mathbf{5 ~ - - >}$ & 1,57 & 13,76 & 1,8 & 15,52 & \\
$\mathbf{6 ~ - - >}$ & 1,57 & 1,57 & 12,81 & 15,52 & Error +1, kode guru sama antar kelas \\
& & & & & (kode 57) \\
$\mathbf{7 ~ - - >}$ & 3,63 & 1,57 & 12,81 & 12,81 & \\
$\mathbf{8 - - >}$ & 3,63 & 5,14 & 12,81 & 12,81 & $\begin{array}{l}\text { Error }+1, \text { kode olahraga bukan jam pagi } \\
\text { (kode 12 jam ke 7) }\end{array}$
\end{tabular}




\section{Total error $=2$}

$$
\text { Fitness }=\frac{1}{1+\text { Error }} \cdot 100
$$

\section{Seleksi Roulette}

Roulette Wheel memungkinkan adanya kromosom yang tetap terjaga. Proses dalam melakukan seleksi Roulette Wheel adalah sebagai berikut:

$$
\text { Nilai Probabilitas }=\frac{\text { nilai fitness }}{\text { total nilai fitness semua individu }} \times 100
$$

Setiap kromosom memiliki kisaran probabilitas tertentu sesuai dengan nilai fitness.

Nilai fitnesss :

kromosom $[1]=3.5$

kromosom[2] $=6$

dst ...

Total nilai fitness $=$ kromosom $[1]+\ldots+$ kromosom $[\mathrm{n}]=100$

Maka nilai probabilitas untuk kromosom[1] adalah $=3.5 / 100=0.035$

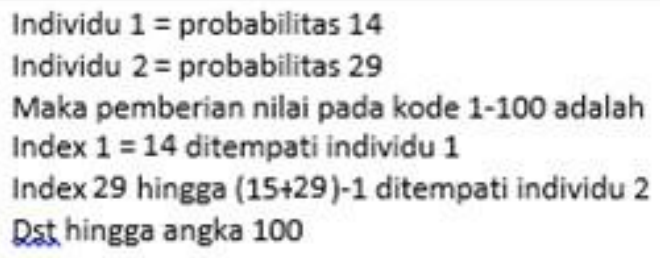

Gambar 2. Bentuk struktur data probabilitas

Dari gambar 2. diatas dijelaskan total probabilitas adalah 100, berdasarkan gambar diatas index probabilitas posisi 1 sampai 14 ditempati individu 1 , posisi 15 sampai $(15+29)-1$ ditempati individu 2 dan seterusnya.

\section{Crossover}

Mekanisme crossover Algoritma Genetika pada kasus penjadwalan Mata Pelajaran Sekolah adalah sebagai berikut:

a) Membagi kromosom berpasang-pasangan ganjil dan ganjil. Susunannya adalah sebagai berikut: 1 dan 3, 2 dan 4, 5 dan 7, 6 dan 8 . Hingga terdapat 10 pasangan crossover dari 20 kromosom yang ada.

b) Hasil crossover di bawah ini adalah model ujicoba crossover pada kromosom 1 (indeks nomor 1) dan kromosom 2 (indeks nomor 2) dan dipotong pada kolom ke satu. Mekanisme crossover sebagai berikut :

Tabel 5. Mekanisme crossover

\begin{tabular}{ll}
\hline Kromosom 1 & Kromosom 2 \\
\hline $1--->12,4,9,17$, & $1--->17,6,6,10$, \\
$2--->13,14,12,5$ & $2--->18,3,11,2$, \\
$3-->16,10,14,11$, & $3-->7,13,5,11$, \\
$4-->5,5,18,6$, & $4-->5,17,13,13$, \\
\hline
\end{tabular}


5 --- > 8, 11, 5, 10, $\quad 5$--- > 12, 2, 15, 5,

Setelah crossover dipotong kolom bagian pertama

1 --- > $12,6,6,10$,

$2-->13,3,11,2$,

3 --- > 16, 13, 5, 11,

4 --- > 5, 17, 13,13,

$5-->8,2,15,5$,

Indek pertama dari kromosom 1 diambil dan semua index dari kromosom ke 2 diambil kecuali index pertama, kemudian index pertama dari kromosom pertama digabungkan dengan index yang diambil dari kromosom ke 2 dan didapatkan kromosom baru dengan data index crossover dari kromosom 1 dengan kromosom 2.

Setelah selesai proses crossover kemudian dihitung ulang nilai fitness dan probabilitas untuk menentukan kromosom yang terbaik.

\section{Mutation}

Langkah-langkah mutasi dilakukan dengan proses sebagai berikut:

a) Menentukan mutation rate. Yaitu harga acak yang menentukan probabilitas sebuah individu melakukan mutasi. Harga yang ditentukan dalam aplikasi ini adalah $5 \%$. Harga ini dapat diubah-ubah.

b) Jika sebuah individu memenuhi syarat, proses berikutnya adalah mengacak lokasi deret gen. Misal hasil pengacakan adalah deret ke 3, maka perlakukan mutasi dilakukan untuk gen dengan nomor deret ke 3 . Deret gen yang mengalami perlakukan mutasi akan dibuang dan diganti dengan deret gen yang baru. Mekanisme mutation sebagai berikut :

Tabel 6. Mekanisme mutation

\begin{tabular}{lcc}
\hline \multicolumn{1}{c}{ Sebelum mutasi } & $\begin{array}{c}\text { Sususan } \\
\text { gen untuk mutasi }\end{array}$ & \multicolumn{1}{c}{ Setelah mutasi } \\
\hline $3-->9,10,3,15$, & 19 & $3->9,19,3,15$, \\
$3->1,12,10,18$, & 18 & $3->1,18,10,18$, \\
$3->17,14,8,14$, & 5 & $3->17,5,8,14$, \\
$3->>8,8,14,10$, & 17 & $3->8,17,14,10$, \\
$3->4,19,15,12$, & 0 & $3->4,0,15,12$, \\
$3->16,6,16,8$, & 14 & $3->16,14,16,8$, \\
$3->>15,7,2,5$, & 9 & $3->15,9,2,5$, \\
$3->18,11,17,2$, & 7 & $3->18,7,17,2$, \\
$3-->10,1,1,1$, & 13 & $3->10,13,1,1$, \\
$3->>3,9,0,0$, & 8 & $3->3,8,0,0$, \\
\hline
\end{tabular}

Indek ke tiga dari kromosom diambil dan kemudian dilakukan proses pengacakan data sehingga posisi awal akan berubah. Setelah selesai proses mutation kemudian dihitung ulang nilai fitness dan probabilitas untuk menentukan kromosom yang terbaik. 
- Desain Antarmuka

Desain antarmuka (interface) adalah bentuk implemenetasi system berbasis web yang untuk memudahkan penggunaan dan pembacaan program. Pilih menu buat jadwal dan ini mata pelajaran kemudian klik Buat Jadwal yang tertera pada gambar 3.

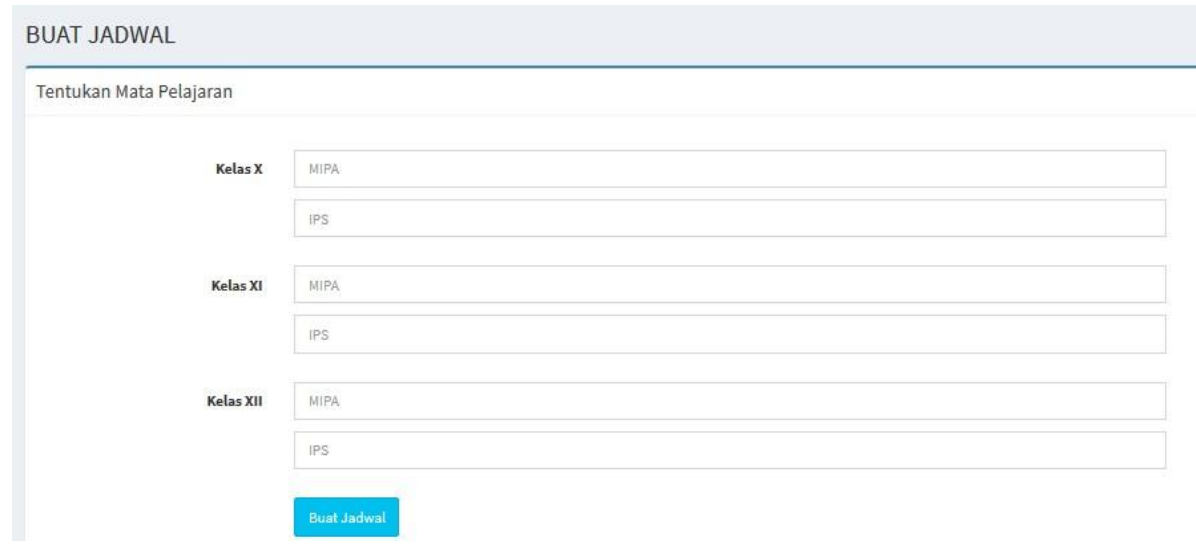

Gambar 3. Halaman pembuatan jadwal

Karena mata pelajaran tiap jenjang berbeda maka untuk proses pembuatan jadwal diperlukan input pemilihan data mata pelajaran untuk kelas X,XI, dan XII. Berikut pada gambar 4 adalah interfase pemilihan mata pelajaran.

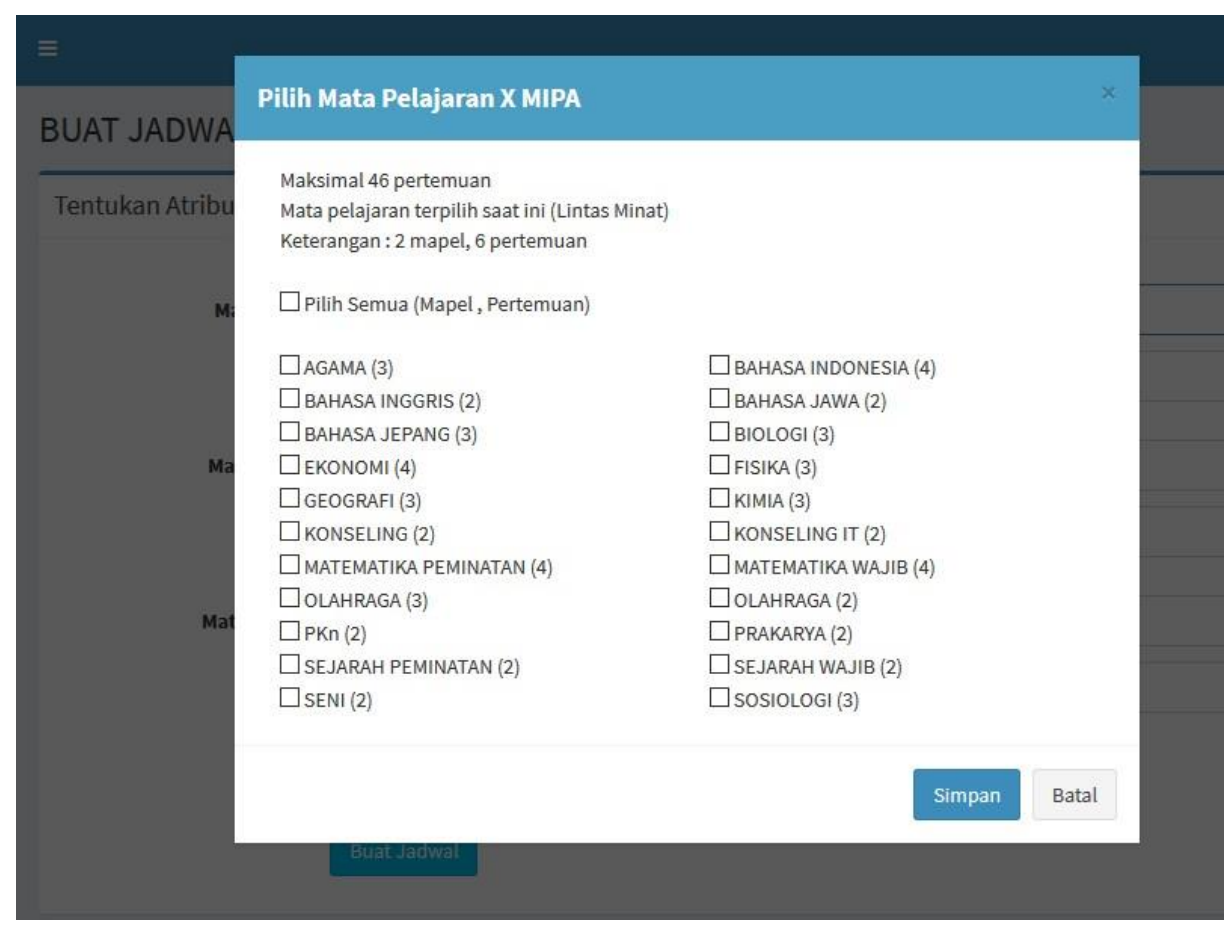

Gambar 4. Halaman pemilihan mata pelajaran

Sebelum memilih mata pelajaran sebelumnya telah di tentukan mata pelajaran Lintas Minat dimata setiap kelas berbeda, maksimlah pertemuan dihitung dari hari senin jam pertemuan 1 sampai hari jum'at pertemuan ke 6. Setelah memilih mata pelajaran kemudian klik Simpan. 


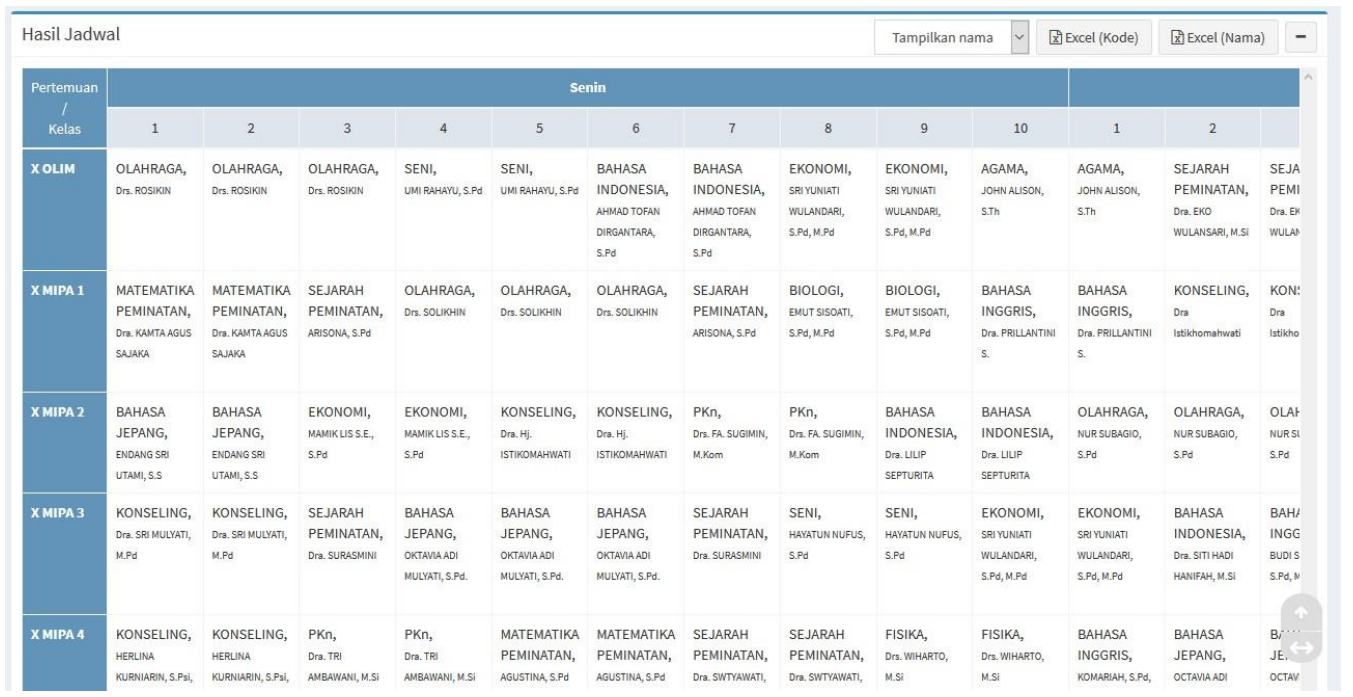

Gambar 5. Hasil Penjadwalan Akhir (WEB)

Pada gambar 5 hasil penjadwalan dapat ditampilkan dalam bentuk kode huruf atau kode angka dan dapat dilakukan download file excel untuk melihat jadwal.

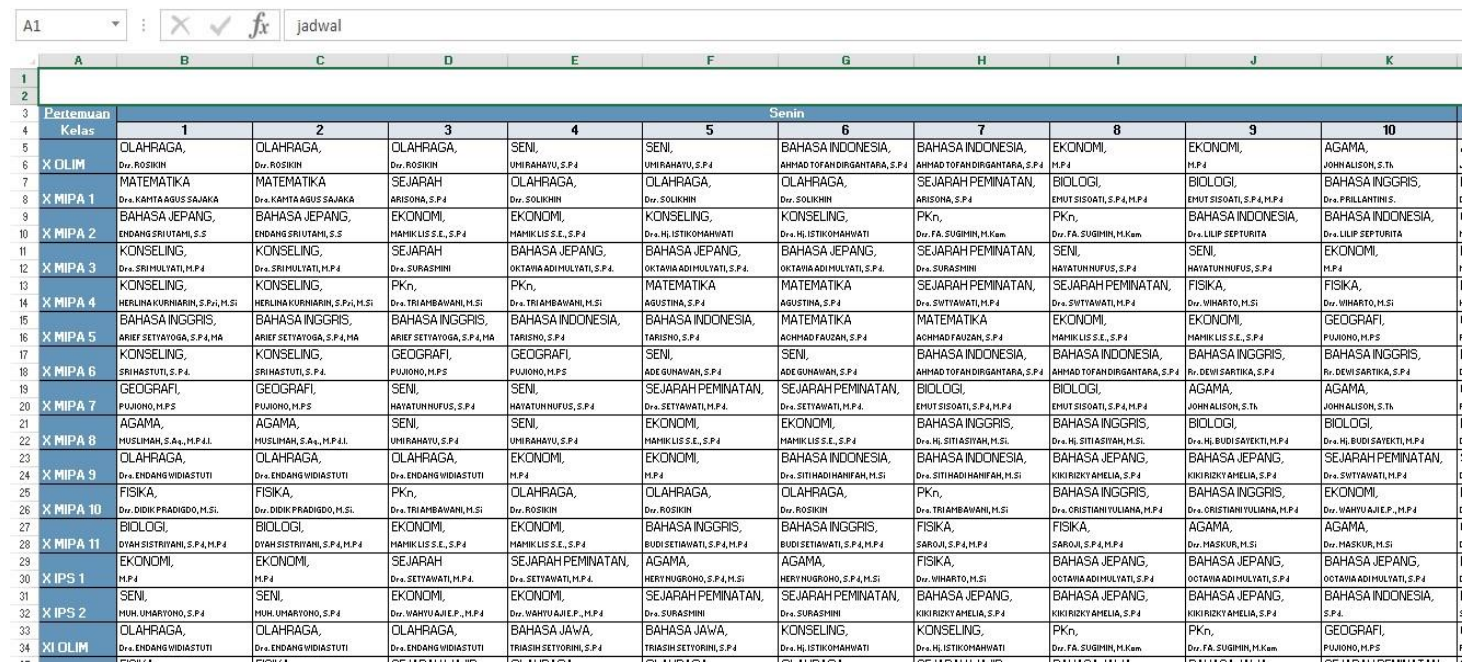

Gambar 6. Hasil Penjadwalan Akhir (Excel)

Pada gambar 6 hasil excel dapat berupa kode huruf atau nama asli dari setiap mata pelajaran dan guru.

- Pengujian Sistem

Dilakukan beberapa pengujian diantaranya :

1. Functionally.

Dalam kaitanya dengan standar yang digunakan untuk menentukan apakah sebuah perangkat lunak lolos dalam pengujian faktor kualitas functionality mestinya yang ada pada tabel 7. Fungsi-fungsi dalam pembuatan suatu perangkat lunak dibagi menjadi dua yaitu: primary function (fungsi primer) dan contributing function (fungsi pendukung). Fungsi primer merupakan fungsi yang utama dalam perangkat lunak, kesalahan dalam fungsi ini akan membuat perangkat lunak tidak layak atau tidak dapat digunakan. Sedangkan fungsi pendukung merupakan fungsi yang memberikan kontribusi pada perangkat lunak, tetapi bukan merupakan fungsi utama. 
Tabel 7. Kriteria Kelosan Dalam Aspek Functionally

\begin{tabular}{|c|c|c|c|}
\hline \multicolumn{2}{|r|}{ Kriteria Lolos } & \multicolumn{2}{|r|}{ Kriteria Gagal } \\
\hline 1 & $\begin{array}{l}\text { Setiap fungsi primer yang diuji berjalan } \\
\text { sebagaimana mestinya }\end{array}$ & 1 & $\begin{array}{l}\text { Paling tidak ada satu fungsi primer } \\
\text { yang diuji tidak berjalan } \\
\text { sebagaimana }\end{array}$ \\
\hline 2 & $\begin{array}{l}\text { Jika ada fungsi pendukung Yang tidak } \\
\text { berjalan sebagaimana mestinya, tetapi } \\
\text { itu bukan kesalahan yang serius dan } \\
\text { tidak berpengaruh pada penggunaan } \\
\text { normal }\end{array}$ & 2 & $\begin{array}{l}\text { Jika ada fungsi pendukung Tidak } \\
\text { berjalan sebagaimana mestinya } \\
\text { dan itu merupakan kesalahan yang } \\
\text { serius dan berpengaruh pada } \\
\text { penggunaan normal }\end{array}$ \\
\hline
\end{tabular}

Tabel 8. Hasil Uji functionally

\begin{tabular}{cl}
\hline \multicolumn{1}{c}{ Hasil Pengujian } & Keterangan \\
\hline $\begin{array}{l}\text { Semua fungsi primer dan fungsi } \\
\text { pendukung berjalan dengan baik }\end{array}$ & Lolos \\
\hline
\end{tabular}

Berdasarkan nilai kelolosan pada uji functionally di tabel 8, maka dapat disimpulkan bahwa Software Penjadwalan Mata Pelajaran Sekolah menggunakan Algoritma Genetika telah lolos uji functionally.

\section{Corretness}

Penghitungan jumlah error dilakukan dengan firebug dan tidak ditemukan error pada kode program.

\section{Portability}

Uji portability dilakukan saat ini adalah pada OS windows 7,8,10 dan Mac OS Lion.

Hasil uji coba sistem berjalan dengan normal.

\section{KESIMPULAN}

Berdasarkan uraian rangkaian penelitian Aplikasi Genetika Untuk Penjadwalan Mata Pelajaran di SMAN 3 Semarang maka dapat ditarik kesimpulan sebagai berikut:

1. Pendekatan Algoritma Genetika dalam penyelesaian masalah konstrain penjadwalan sekolah dapat berhasil karena mampu mencari kombinasi penjadwalan yang tepat dengan nilai fitness maksimal, nilai error minimal (ditemukan nilai error 0 ), dan solusi yang optimal (tidak terjadinya tabrakan jadwal pelajaran dan tidak terjadinya kejadian yang menimbulkan peningkatan nilai error).

2. Aplikasi Genetika Untuk Penjadwalan Mata Pelajaran di SMAN 3 Semarang telah diuji dengan kualitas correctness menggunakan kaidah KLOC dan menghasilkan nilai bugs sejumlah 0 line(s). Ini membuktikan bahwa Aplikasi Genetika Untuk Penjadwalan Mata Pelajaran di SMAN 3 Semarang telah memenuhi standar kualitas correctness. Kemudian diuji dengan kualitas functionally dan menghasilkan catatan alur fungsi primer dan fungsi sekunder telah berjalan dengan baik. Ini membuktikan bahwa aplikasi tersebut telah memenuhi standar kaidah functionally. Berdasarkan aspek portability, Aplikasi Genetika Untuk Penjadwalan Mata Pelajaran di SMAN 3 Semarang telah diujikan untuk beberapa environmental atau sistem operasi komputer yang berbeda-beda dan berhasil berjalan baik di semua kondisi. Hal ini menunjukkan bahwa Aplikasi Genetika Untuk Penjadwalan Mata Pelajaran di SMAN 3 Semarang telah memenuhi standar portabilitas yang baik. 


\section{SARAN}

Beberapa saran yang dapat digunakan dalam penelitian ini adalah sebagai berikut:

1. Aplikasi Genetika Untuk Penjadwalan Mata Pelajaran di SMAN 3 Semarang baru memiliki dua constraint nilai error yaitu tabrakan jadwal dan kemuculan mata pelajaran olahraga di siang hari. Dalam penelitian selanjutnya, diharapkan constraint nilai error dapat ditambahkan dan ikut dihitung dalam pembobotan nilai fitness semisal randomisasi guru, mata pelajaran ganjil, dan randomisasi mata pelajaran.

2. Penelitian perangkat lunak baru diuji dalam empat aspek yaitu correctness, functionally dan portability. Dalam penelitian selanjutnya diharapkan aspek yang lain dapat ikut disertakan.

\section{DAFTAR PUSTAKA}

[1] D. D. P. Sari, W. F. Mahmudy, and D. E. Ratnawati, "Optimasi Penjadwalan Mata Pelajaran Menggunakan Algoritma Genetika ( Studi Kasus : SMPN 1 Gondang Mojokerto )," Univ. Brawijaya, vol. 5, no. 13, pp. 1-9, 2015.

[2] E. Satriyanto, "Algoritma Genetika," informatika.web.id, 2011. [Online]. Available: http://informatika.web.id/algoritma-genetika.htm. [Accessed: 15-Mar-2014].

[3] E. Suhartono, "DENGAN ALGORITMA GENETIKA ( Studi Kasus di AMIK JTC Semarang ),"Infokam, vol. 2, pp. 132-146, 2015.

[4] E. Desiana, "Performance Algoritma Genetika (GA) Pada Penjadwalan Mata Pelajaran," J. Nas Inform. dan Teknol. Jar., vol. 1, no. 1, pp. 56-60, 2016.

[5] P. Universitas and D. Nuswantoro, "Penjadwalan Perkuliahan Otomatis Berbasis Fuzzy Logic dan Genetic Algorithm," vol. 14, no. 4, pp. 315-328, 2015.

[6] V. Witary, N. Rachmat, and Inayatullah, "Optimasi Penjadwalan Perkuliahan dengan Menggunakan Algoritma Genetika ( Studi Kasus : AMIK MDP , STMIK GI MDP dan STIE MDP )," J. STMIK GI MDP, pp. 1-7, 2013. 